\title{
Studies on Short-Term Storage of Leafy Vegetable (Spinach) in Zero Energy Cool Chamber with Gravity Fed Micro-Dripper Watering System
}

\author{
M. K. Ghosal ${ }^{1 *}$, Sushree Titikshya ${ }^{2}$ and G. Manasi Mohapatra ${ }^{2}$ \\ 1Professor, Department of Farm Machinery and Power, College of Agricultural Engineering and Technology, Orissa University of \\ Agriculture and Technology (OUAT), Bhubaneswar-751003, Odisha, India \\ 2Ex-B. Tech. Students, Department of Farm Machinery and Power, College of Agricultural Engineering and Technology, Orissa \\ University of Agriculture and Technology (OUAT), Bhubaneswar-751003, Odisha, India
}

\section{${ }^{*}$ Corresponding Author \\ M. K. Ghosal}

\section{Article History}

Received: 02.09.2019

Accepted: 09.10.2019

Published: 11.11.2019

\begin{abstract}
Leafy vegetables (greens) are highly perishable and need immediate storage in a favourable environment after harvest for maintaining their freshness and marketability. Their importance is now-a-days gaining momentum among the consumers because of various health benefits. However, farmers are not interested to grow leafy vegetables due to their high perishability and lack of proper storage facilities which force them to sell their harvested material immediately at a lower price, resulting ultimately in reduced net profit to the growers. An attempt has therefore been made in this paper to study the feasibility of using a low cost and very low energy consuming storage device for short-term storage of leafy vegetable (spinach) of about 1 week and to encourage the farmers to go for cultivating greens in a small scale mostly in their back yard for achieving nutritional and livelihood security. One such storage device used for the present study is zero energy cool chamber, constructed at OUAT, Bhubaneswar, Odisha, India. The Zero energy cool chamber for this study was provided with a gravity fed micro-dripper watering system for uniform and continuous wetting of sand bed. A zero energy cool chamber constructed in coastal area of Odisha i.e. at Bhubaneswar was used to study the storability of most prevailing leafy vegetable i.e. spinach during April-May 2015. It was found that spinach could be stored 4 days in the marketable form in zero energy cool chamber under coastal conditions compared to 1 day in room condition (temperature, $23-27^{\circ} \mathrm{C}$ and $\mathrm{Rh}, 50-60 \%$ ) during summer period.
\end{abstract}

Keywords: Leafy vegetables, Zero energy cool chamber, Micro-dripper, Evaporative cooling, Shelf-life.

\section{INTRODUCTION}

Leafy vegetables (greens) with increasing recognition of their value in the human diet are now-a-days gaining commercial importance in the agricultural sector. They are rich in many nutrients. Per unit nutritive value and cost of leafy vegetables are cheapest among other vegetables and are affordable to all categories of people. They are very rich in iron, carotene, calcium, vitamins A, C, riboflavin and folic acid [1]. The most cultivated greens in the state Odisha, India are amaranthus and spinach which possess considerable nutritional quality that help in protecting the body against various diseases. However, greens are rarely found in the daily diet of the majority of people living in the villages. Lack of awareness regarding the health benefits of greens and their non-availability as per the requirements is the major causes for poor consumption of the product among the village people. The major factor limiting the cultivation of leafy vegetables by marginal and small farmers is the highly perishable nature of the produce which forces the farmers to sell the harvested material immediately to whatever prices offered to them, ultimately resulting in reduced net profit to the growers. The leafy vegetables generally get deteriorated at a faster rate than other vegetables because of large leaf surface to weight ratio causing a very high respiration rate [2]. They get deteriorated even after 5-6 hours of harvesting due to harsh climatic conditions [3]. In order to extend their shelf life, they need to be properly stored. Proper storage means controlling both the temperature and relative humidity of the storage area. Reducing temperature and increasing humidity inside the stored chamber are required to maintain freshness and to enhance shelf-life. The recommended storage temperature and humidity for greens are about $4-8{ }^{\circ} \mathrm{C}$ and 90-95\% respectively to attain their shelf-life of around 12-18 days [4]. Establishment of a cold chain facility is though considered ideal for storage of vegetables, it would take a long way to establish such a system in our country, to the extent of benefitting even the small

Copyright @ 2019: This is an open-access article distributed under the terms of the Creative Commons Attribution license which permits unrestricted use, distribution, and reproduction in any medium for non commercial use (NonCommercial, or CC-BY-NC) provided the original author and source are credited. 
and marginal farmers, scattered in areas which are far off and not well connected to the major markets. Farmers and traders still practice their age-old storage methods leading to large-scale wastage during storage and transportation [5]. The problem is further made complex with prevailing energy crisis and energy cost for mechanical refrigeration system. Considering the present circumstances, development and popularization of any storage technology which is cheaper and does not depend on non renewable energy sources and high technologies, could largely benefit the small and marginal farmers in on-farm storage of their produce for a shorter period so that they could accumulate their harvested produce over a few days and take them to the market for getting a reasonable price.

Hence, the essence of storage is of great importance because not all the harvested leafy vegetables in general will be used immediately after their harvest. Measures of preserving the vegetables before it exceeds its shelf life are also highly necessary. Most of the farmers are not able to afford the cost of purchasing high-tech storage equipments for their harvested crops. Evaporative cooling has been found to be an effective and economical means of reducing temperatures and increasing humidity in an enclosure where the humidity is comparatively low [6-8]. Minimizing deteriorative reactions in vegetables enhances their shelf lives, implying that the produce will be available for longer periods; this would reduce fluctuation in market supply and prices. Evaporative cooler works on the principle of cooling resulting from evaporation of water from the surface of the structure. The cooling achieved by this device also results in high relative humidity of the air in the cooling chamber from which the evaporation takes place relative to ambient air [9]. The atmosphere in the chamber thus becomes more conducive for storage of vegetables. Therefore, it is required to develop and popularize a low cost, less energy consuming and environment friendly cool chamber which would not only be affordable for resource poor farmers but also for safe storage of the greens for a short period, resulting into a prospect of getting remunerative price of the produce. The evaporative cooling systems have prospect for use for short term preservation of vegetables after harvesting [10]. It reduces the storage temperature and also increases the relative humidity within the optimum level of the storage thereby helps in keeping the vegetables fresh.

In order to overcome the problem of on-farm storage, low cost environment friendly Pusa Zero Energy Cool Chambers have been developed [11]. The Zero Energy Cool Chamber was initially developed by Dr. S.K. Roy during 1980's at the Indian Agricultural Research Institute, Pusa, New Delhi and has been field tested and redesigned over the past few years to improve its function. Though this technology of on-farm storage of fruits and vegetables for shorter periods had been developed long back, the efforts to popularize this technology are now gaining momentum because of today's increasing post harvest losses, rising environmental concern and growing cost of power. This is almost similar to earthen pots widely used to cool water. Transfer of heat due to evaporation of water from the surface of the cooling vessel ultimately leads to cooling the atmosphere within the vessel. The water contained in the sand between the two brick walls evaporates towards the outer surface of the outer wall, where the drier outside air is circulating. By virtue of the laws of thermodynamics, the evaporation process automatically causes a drop in temperature of several degrees, cooling the inner container and preserving the vegetables inside [12]. Hence, looking towards health, employment and income of small and marginal farmers through cultivation of greens in a small scale round the year in their unutilized back yard, an attempt has been made to study the feasibility of cultivating leafy vegetables in a small patch of land, to store the harvested produce in a low cost zero energy cool chamber for a short period and subsequently to sell the product in the marketable form for maintaining its economic viability and livelihood security. The importance of this low cost cooling technology lies on the fact that it does not require any electricity or power to operate and all the materials required to construct the cool chamber are available easily at cheaper cost. Even an unskilled person can install it at any site, as it does not involve any specialized skill. Most of the raw materials used in cool chamber are also reusable. Zero energy cool chamber can retain the freshness of the fruits and vegetables for a short period [13]. Small farmers can easily construct these chambers nearer to their houses or fields in order to store their harvested produce. In this way, the farmers can store their produce for few days and send the bulk of the commodity to the whole sale market so that they will not be forced to make any distress sale in the local market because in India almost 90 per cent of horticultural produce is sold in fresh form. The involvement of middle men in making this distress sale increases the price of horticultural produces by 60-100 per cent in retail outlets compared to the growing areas [14]. The strategy of on-farm storage of vegetables harvested daily in small quantities over few days and sending them to distant markets without solely depending on the local market can definitely augment the income of the farmers. The cool chamber can reduce the temperature by few degrees and maintain a high relative humidity compared to ambience, thereby helping in enhancing the freshness of the produce $[15,16]$. Keeping this in view, the present study is undertaken to evaluate the efficacy of IARI design Zero Energy Cool Chamber with a modification of using gravity fed micro dripper for uniform and continuous wetting of sand bed for effective evaporative cooling in enhancing the shelf-life of leafy vegetables under coastal conditions.

The objectives of the present study are therefore (i) to study the quality and shelf-life of leafy vegetable (spinach) stored in zero energy cool chamber (ii) to compare the storability of spinach both in zero energy cool chamber and in room condition and (iii) to study the cost of cultivation of spinach grown in a kitchen garden or adjacent area surrounding the house

\section{Materials ANd Methods}

An experiment was conducted during the year 2015 to evaluate the efficacy of zero energy cool chamber on the storability of leafy vegetable (spinach). The leafy vegetable was grown in $200 \mathrm{~m}^{2}(20 \mathrm{~m} \times 10 \mathrm{~m})$ in the central farm of Odisha University of Agriculture and Technology (OUAT) from February-April 2015. The zero energy cool chamber (Fig-1) has been constructed in the premises of College of Agricultural Engineering and Technology, OUAT, Bhubaneswar, which is coming under warm and humid 
climatic region and in the coastal belt of Odisha. The quality of the stored leafy vegetable in zero energy cool chamber with respect to physiological weight loss and rotten percentage, has been studied during peak summer i.e. from 20-28th April 2015 when there was high temperature $\left(35-42^{\circ} \mathrm{C}\right)$ with low relative humidity $(50-65 \%)$ outside.

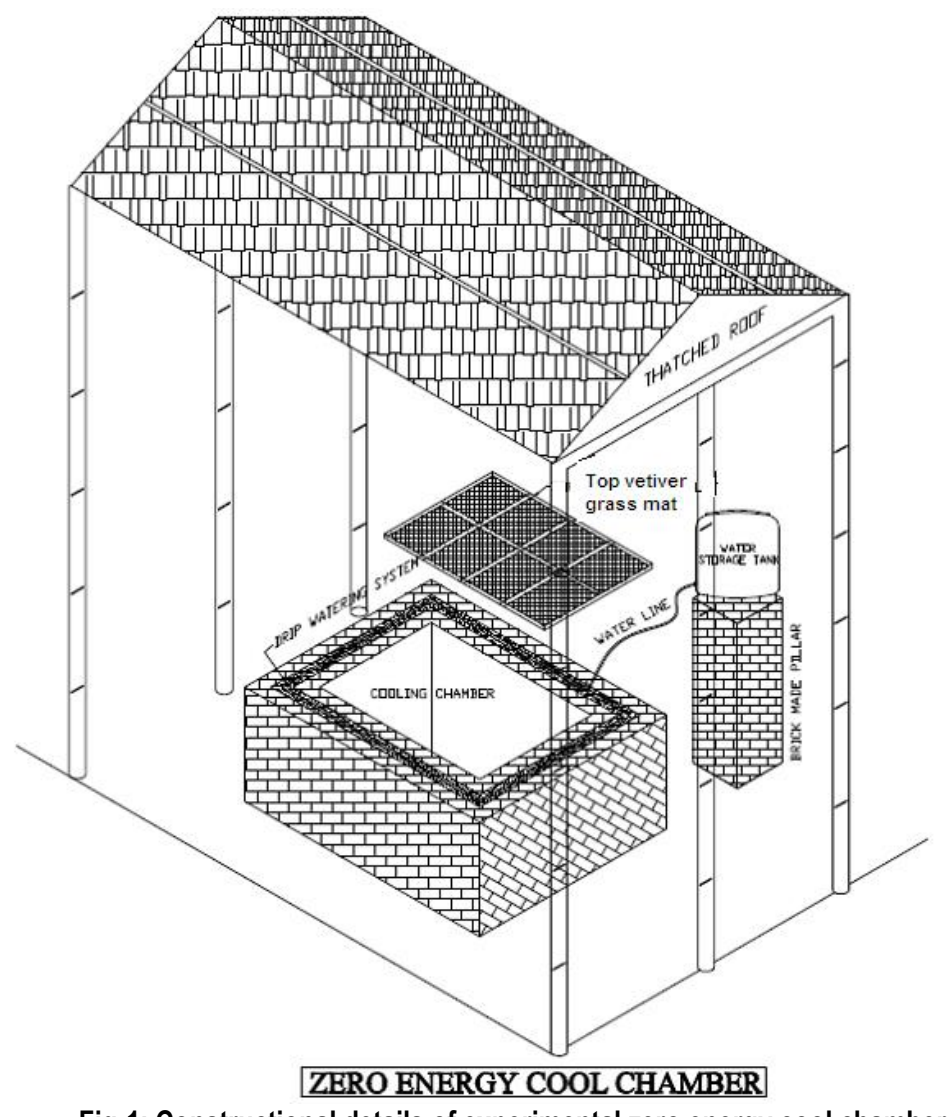

Fig-1: Constructional details of experimental zero energy cool chamber

Zero energy cool chamber is an on-farm rural oriented storage structure which operates on the principle of evaporative cooling and has been constructed using locally available raw materials such as bricks, sand, bamboo, rice straw, vetiver grass, jute cloth etc. The chamber has been constructed above the ground and comprises of a double-walled structure made up of bricks. The cavity of the double wall is filled with riverbed sand. The lid was made by using vetiver grass mat on a bamboo frame. Floor of the chamber was made with the help of bricks and of size $165 \mathrm{~cm} \times 115 \mathrm{~cm}$. the space between the double wall is $7.5 \mathrm{~cm}$, filled with fine sand. After construction of the chamber, the following procedures were adopted for its use.

The walls of the chamber were made wet and the sand in between the double wall was saturated with water by the gravity fed micro-dripper from a 35 litre capacity plastic bucket placed $50 \mathrm{~cm}$ from the top of the chamber. Fresh leafy vegetables to be stored were weighed and taken in perforated polythene bag placed inside the chamber. The chamber was closed completely with the wetted vetiver grass mat. The walls of the chamber as well as the sand filled in the gap of the double wall structure were watered twice daily (morning and afternoon) to maintain high relative humidity and low temperature inside the chamber. The leafy vegetable spinach was kept in zero energy cool chamber to study their storability during peak summer period. The temperature and relative humidity inside the chamber were monitored periodically using a hand held portable $\mathrm{RH} /$ Temperature meter (least count $1 \%$ for $\mathrm{Rh}$ and $0.5{ }^{\circ} \mathrm{C}$ for temperature). Simultaneously a control sample for spinach was also maintained in room condition to compare the effectiveness of zero energy cool chamber (ZECC).

\section{RESULTS AND DISCUSSION}

The loss in weight of the stored leafy vegetable i.e. physiological loss in weight (PLW) is an indication of moisture loss from the produce which renders the leafy vegetables unmarketable as it loses the lusture and freshness. The moisture loss from horticultural produce is not a mere loss of weight rather it is a loss of appearance, taste and even nutrients from the produce which ultimately results in economic loss of the produce. So, any storage method for perishables like leafy vegetables should aim at minimizing the moisture loss and respiration from the produce so as to enhance their keeping quality and marketability. This would be possible by reducing the storage temperature and increasing the relative humidity of air surrounding the produce in the storage atmosphere. The data regarding percentage physiological loss in weight, rotten percentage, comparative prevailing temperatures relative humidity in ZECC, room condition (RC) and ambient condition of leafy vegetable under study were recorded during peak 
summer period and are presented in the tables 1-3. The physiological weight loss in the range of 10-15 percent and rotten percentage to be in the range of 20-30 are allowable for maintaining the freshness and marketability of vegetables $[13,7]$.

Table-1: Physiological loss in weight, PLW (\%) of leafy vegetable during storage period with the use of 70 litres water/day

\begin{tabular}{|c|c|c|c|c|c|c|c|c|c|c|c|c|c|c|}
\hline \multirow[t]{2}{*}{ Leafy Vegetables } & \multicolumn{2}{|c|}{ DAY1 } & \multicolumn{2}{|c|}{ DAY2 } & \multicolumn{2}{|c|}{ DAY3 } & \multicolumn{2}{|c|}{ DAY4 } & \multicolumn{2}{|c|}{ DAY5 } & \multicolumn{2}{|c|}{ DAY6 } & \multicolumn{2}{|c|}{ DAY7 } \\
\hline & ZECC & $\mathrm{RC}$ & ZECC & $\mathrm{RC}$ & ZECC & $\mathrm{RC}$ & ZECC & $\mathrm{RC}$ & ZECC & $\mathrm{RC}$ & ZECC & $\mathrm{RC}$ & ZECC & $\mathrm{RC}$ \\
\hline Spinach & 4.92 & 14.97 & 7.55 & 40.38 & 11.64 & Spoiled & 14.35 & ------ & 15.57 & 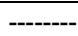 & 20.66 & --.-- & 57.94 & - \\
\hline
\end{tabular}
ZECC (Zero energy cool chamber), RC (Room condition)

Table-2: Percentage of rotten/unmarketable leafy vegetable during storage period

\begin{tabular}{|c|c|c|c|c|c|c|c|c|c|c|c|c|c|c|}
\hline \multirow[t]{2}{*}{ Leafy Vegetables } & \multicolumn{2}{|c|}{ DAY1 } & \multicolumn{2}{|c|}{ DAY2 } & \multicolumn{2}{|c|}{ DAY3 } & \multicolumn{2}{|c|}{ DAY4 } & \multicolumn{2}{|c|}{ DAY5 } & \multicolumn{2}{|c|}{ DAY6 } & \multicolumn{2}{|c|}{ DAY7 } \\
\hline & ZECC & $\mathrm{RC}$ & ZECC & $\mathrm{RC}$ & ZECC & $\mathrm{RC}$ & ZECC & $\mathrm{RC}$ & ZECC & RC. & ZECC & RC. & ZECC & RC. \\
\hline Spinach & ------. & 28.87 & 5.45 & 36.78 & 10.44 & Spoiled & 20.54 & $-\cdots$ & Spoiled & ----- & $-\cdots$ & ----- & 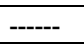 & ---- \\
\hline
\end{tabular}

Table-3: Experimental temperature and humidity for storage of some leafy vegetable in ZECC and Room Condition during study period in summer condition

\begin{tabular}{|c|c|c|c|c|c|c|c|c|c|}
\hline \multirow[t]{2}{*}{$\begin{array}{l}\text { Name of leafy } \\
\text { vegetables }\end{array}$} & \multicolumn{3}{|c|}{$\begin{array}{l}\text { Recommended temperature and humidity } \\
\text { and shelf-life (day) (Anon. 2013) }\end{array}$} & \multicolumn{3}{|c|}{$\begin{array}{l}\text { Experimental Temp., humidity and } \\
\text { shelf-life (day) in ZECC }\end{array}$} & \multicolumn{3}{|c|}{$\begin{array}{l}\text { Experimental Temp., humidity and } \\
\text { shelf-life (day) in Room Condition }\end{array}$} \\
\hline & Temp $\left({ }^{\circ} \mathrm{C}\right)$ & $\operatorname{Rh}(\%)$ & Shelf-life (day) & $\begin{array}{l}\text { Temp } \\
\left({ }^{\circ} \mathrm{C}\right)\end{array}$ & $\begin{array}{l}\mathrm{Rh} \\
(\%)\end{array}$ & $\begin{array}{l}\text { Shelf-life } \\
\text { (day) }\end{array}$ & $\begin{array}{l}\text { Temp } \\
\left({ }^{\circ} \mathrm{C}\right)\end{array}$ & $\begin{array}{l}\mathrm{Rh} \\
(\%)\end{array}$ & Shelf-life (day) \\
\hline Spinach & $5-8$ & $90-95$ & $8-10$ & $20-33$ & $80-95$ & 4 & 24-37 & $60-78$ & 1 \\
\hline
\end{tabular}

From the experiments, it was found that there were decrease in temperatures in the range of $3^{\circ} \mathrm{C}$ to $7^{\circ} \mathrm{C}$ and increase in $\mathrm{RH}$ by 12 to 26 per cent inside the ZECC compared to room conditions at various times of a day. Similarly, decrease in temperature in the range of $6^{\circ} \mathrm{C}$ to $10^{\circ} \mathrm{C}$ and increase in $\mathrm{RH}$ by 25 to 40 per cent inside the ZECC compared to outside ambient condition were recorded at various times of a day during the experimental observations. The highest differences were mostly observed at $2.00 \mathrm{pm}$. The physiological loss in weight (PLW) recorded for spinach on day 4 of storage inside the Zero Energy Cool Chamber (ZECC) was only 14.35 per cent as against 14.97 per cent in room condition on Day 1 . The rotten percentages were recorded to be only 20.54 on day 4 and 28.87 on Day 1 in ZECC and room condition respectively. Considering the PLW (14.35 per cent) and rotten/ unmarketable greens (20.54 per cent) together, spinach could be well stored in the ZECC for 4 days. Similarly, allowing PLW (14.97 per cent) and rotten/ unmarketable greens (28.87per cent) together after 1 day, spinach could be well stored in the room condition only for 1 day. Considering the PLW (10.32 per cent) and rotten/ unmarketable greens (10.98 per cent) together, spinach could be well stored in the ZECC for 2 days. In the summer period, it was found that spinach could be stored 4 days in the marketable form in ZECC under coastal conditions compared to 1 day in room condition.

\section{CONCLUSION}

One of the major constraints faced by marginal and small farmers engaged in cultivation of leafy vegetables is the perishability of the produce which forces them to sell the produce to whatever prices offered in the nearby market point. Taking the produce to a distant market is not feasible owing to the small quantity of sundry leafy vegetables being harvested every day. On the other hand, the consumers are also paying a high price for a poor quality produce as there is no cold chain market facilities established in rural and sub urban areas. Considering the above constraints, the farmers interested for growing various leafy vegetables on a smaller area should have some alternate technologies for storing their produce at least for a shorter period (5-7 days) so that the everyday's harvest could be accumulated and taking a bigger volume of the produce once in a few days to the market becomes an economically viable option for the growers and the consumers can also be benefited by the availability of fresh and nutritious leafy vegetables. Nowadays, evaporative cooled storage system is increasingly being used for on-farm storage of fruits and vegetables as it not only lowers the air temperature surrounding the produce, it also increases the moisture content of the air. This helps preventing the moisture loss of the produce, therefore extends the shelf life of leafy vegetables. Zero Energy Cool Chamber which works exclusively on the principle of evaporative cooling could be used effectively for short duration storage of leafy vegetables with almost on energy consumption and low investment suitable for small and marginal farmers for on-farm storage of their produce. It not only reduces the storage temperature but also increases the relative humidity of the storage which is essential for maintaining the freshness of the commodities like leafy vegetables.

\section{REFERENCES}

1. Mogaji, T. S., \& Fapetu, O. P. (2011). Development of an evaporative cooling system for the preservation of fresh vegetables. African Journal of Food Science, 5(4), 255-266.

2. Jany, M. N. H., Sarker, C., Mazumder, M. A. R., \& Shikder, M. F. H. (2008). Effect of storage conditions on quality and shelf life of selected winter vegetables. Journal Bangladesh Agricultural University, 6(2): 391-400.

3. Islam, M. P., Morimoto, T. K., Hatou, L. H., Awal, M. A., \& Hossain, S. T. (2013). Case study about field trial responses of zero energy storage system. December 2013. Agricultural Engineering. Int: CIGR Journal, 15(4): 113-118. 
4. Singh, R. K. P., \& Satpathy, K. K. (2006). Performance evaluation of zero energy cool chamber in hilly region. Agricultural Engineering Today, 30(5 \&6): 47-56.

5. Kanak, L., \& Sanjay, S. (2013). Cost effective on farm storage: zero energy cool chamber for the farmers of Gujarat. Asian Journal of Horticulture, 8(1), 50-53.

6. Jain, D. (2007). Development and testing of two-stage evaporative cooler. Building and Environment, 2549-2554.

7. Jha, S. N. (2008). Development of a pilot scale evaporative cooled storage structure for fruits and vegetables for hot and dry region. JOURNAL OF FOOD SCIENCE AND TECHNOLOGY-MYSORE, 45(2), 148-151.

8. Jadhav, R. T., Yadav, A. N., Ghag, K. S., \& Gavnang, M. R. (2010). Comparative study oflow cost evaporative cooling systems for storage of tomato. International Journal of Agricultural Engineering. 3(2): 199-204.

9. Ashrae. (2003). Evaporative Cooling System. American Society of Heating and Refrigeration and Air Conditioning.www.ashare.com

10. Liberty, J. T., Ugwuishiwu, B. O., Pukuma, S. A., \& Odo, C. E. (2013). Principles and application of evaporative cooling systems for fruits and vegetables preservation. International Journal of Current Engineering and Technology, 3(3), 1000-1006.

11. Roy, S. K., \& Pal, R. K. (1991). A low cost zero energy cool chamber for short term storage of mango. Acta Horticulture, 291(1): 519-524.

12. Mordi, J. I., \& Olorunda, A. O. (2003). Effect of evaporative cooler environment on the visual qualities and storage life of fresh tomatoes. Journal of Food Science and Technology, 40(6), 587-591.

13. Olosunde, W. A. (2006). Performance Evaluation of Absorbent Materials in the Evaporative Cooling System for the Storage of Fruits and Vegetable M. Sc thesis, Department of Agricultural Engineering, University of Ibadan, Ibadan.

14. Anonymous. (2013). Indian Horticulture Data Base-2013. Ministry of Agriculture, Govt. of India.

15. Rayaguru, K., Khan, M. K., \& Sahoo, N. R. (2010). Water use optimization in zero energy cool chambers for short term storage of fruits and vegetables in coastal area. Journal Food Science Technolgy, 47(4):437-441.

16. Islam, M. P., \& Morimoto, T. (2012). Zero energy cool chamber for extending the shelf life of tomato and egg plant. Japan Agricultural research Quarterly, 46(3): 257-267. 